NASA

Technical Memorandum 103710
AVSCOM

Technical Report 91-C-003

\title{
NASA Low-Speed Centrifugal Compressor for 3-D Viscous Code Assessment and Fundamental Flow Physics Research
}

\author{
M.D. Hathaway \\ Propulsion Directorate \\ U.S. Army Aviation Systems Command \\ Lewis Research Center \\ Cleveland, Ohio \\ J.R. Wood \\ National Aeronautics and Space Administration \\ Lewis Research Center \\ Cleveland, Ohio
}

and

C.A. Wasserbauer

Sverdrup Technology, Inc.

Lewis Research Center Group

Brook Park, Ohio

Prepared for the

36th International Gas Turbine and Aeroengine Congress and Exposition sponsored by the American Society of Mechanical Engineers Orlando, Florida, June 3-6, 1991 


\section{NASA LOW-SPEED CENTRIFUGAL COMPRESSOR FOR 3-D VISCOUS CODE ASSESSMENT AND FUNDAMENTAL FLOW PHYSICS RESEARCH}

\author{
M.D. Hathaway \\ Propulsion Directorate \\ U.S. Army Aviation Systems Command \\ Cleveland, Ohio 44135
}

\author{
J.R. Wood \\ NASA Lewis Research Center \\ Cleveland, Ohio 44135
}

\author{
C.A. Wasserbauer \\ Sverdrup Technology, Inc. \\ Lewis Research Center Group \\ Cleveland Ohio 44135
}

\section{ABSTRACT}

A low speed centrifugal compressor facility recently built by the NASA Lewis Research Center is described. The purpose of this facility is to obtain detailed flow field measurements for computational fluid dynamic code assessment and flow physics modelling in support of Army and NASA efforts to advance small gas turbine engine technology. The facility is heavily instrumented with pressure and temperature probes, both in the stationary and rotating frames of reference, and has provisions for flow visualization and laser velocimetry. The facility will accommodate rotational speeds to 2400 $\mathrm{rpm}$ and is rated at pressures to $1.25 \mathrm{~atm}$. The initial compressor stage being tested is geometrically and dynamically representative of modern high-performance centrifugal compressor stages with the exception of Mach number levels. Preliminary experimental investigations of inlet and exit flow uniformity and measurement repeatability are presented. These results demonstrate the high quality of the data which may be expected from this facility. The significance of synergism between computational fluid dynamic analyses and experimentation throughout the development of the low speed centrifugal compressor facility is demonstrated.

\section{NOMENCLATURE}

\section{$\underline{\text { Subscripts }}$}

(0)
= Impeller exit blade height, $\mathrm{cm}$

$=$ Impeller exit tip diameter, $\mathrm{cm}$

$=$ Ideal head rise, $\mathrm{m}$

$=$ rotational speed, $\mathrm{rad} / \mathrm{sec}$

= Volumetric flow rate, $\mathrm{m}^{3} / \mathrm{scc}$

$=$ radius, $\mathrm{cm}$

= rotor blade speed, $\mathrm{m} / \mathrm{sec}$

= Absolute velocity, $\mathrm{m} / \mathrm{sec}$

$=$ Relative velocity, $\mathrm{m} / \mathrm{sec}$

$=$ axial coordinate, $\mathrm{cm}$

= kinematic viscosity, $\mathrm{m}^{2} / \mathrm{sec}$

$$
\begin{aligned}
& =\text { plenum } \\
& =\text { impeller inlet survey station }
\end{aligned}
$$

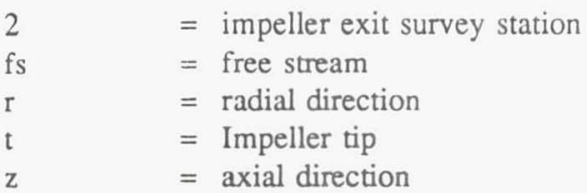

\section{INTRODUCTION}

Centrifugal compressors are widely used in a variety of applications because of their ability to achieve high pressure ratios in a relatively short axial distance and due to their rugged construction. Centrifugal compressors are characterized by long blade channels which have complex in- and out-of-plane turns with high curvature. Due to the complex turning of the flow and rotational forces, strong secondary flows are produced. These secondary flows, along with separated flow regions, lead to strong cross-flow velocity components which transport fluid with low momentum and high totalpressure loss into the main stream. Attempts to model the complex three-dimensional nature of the flow in centrifugal compressors have generally met with little success, although recently a number of investigators have produced numerical computations which show great promise (e g., Moore and Moore, 1989, 1990, Hah et al., 1988, 1989, Dawes, 1988). Designers of centrifugal turbomachines have therefore had to rely heavily on empiricism. As a result, centrifugal compressors tend to have lower efficiencies than their axial-flow counterparts. For significant improvements in the aerodynamic performance of centrifugal compressors to be realized a more detailed understanding of the fundamental flow physics is required. Synergism between experiments and computational analyses will undoubtedly play a key role in developing this understanding.

With the advent of more powerful computers and further development of three-dimensional Navier-Stokes codes, the numerical prediction of centrifugal compressor flow fields has greatly improved. However, assessment of the ability of these predictions to accurately model the fundamental physics of centrifugal compressor flow fields is largely lacking. Krain and Hoffman (1989), Eckart (1976), Joslyn et al. (1990), Young et al. (1987), Japiske and Karon (1989), Hayami et al., (1984), Johnson and Moore (1980, 
1983) have reported measurements of flows in centrifugal compressors which have shed light on many aspects of centrifugal compressor flow physics. Most of these investigations however, have lacked the detailed measurements required to assess the ability of threedimensional viscous codes to accurately model the fundamental flow physics. Furthermore, none of the investigations yielded detailed information within viscous regions ( $i$ e., blade boundary layers).

The NASA Low Speed Centrifugal Compressor (LSCC) was designed and built in order to obtain the detailed measurements which are required to assess three-dimensional viscous codes and to develop more sophisticated models of the various physical phenomena occurring in centrifugal compressors. This paper describes the major components and instrumentation of the low speed centrifugal compressor facility. Experimental investigations of inlet and exit flow uniformity, measurement repeatability and overall performance are also presented which demonstrate the high quality of the data which may be expected from this facility. The significance of synergism between computational fluid dynamic (CFD) analyses and experimentation throughout the development of the low speed centrifugal compressor facility is demonstrated.

\section{FACILITY}

Figure 1 depicts the major elements of the low speed centrifugal compressor facility. Air is drawn in from a filtered vent in the roof past a bank of steam pipes and louvers designed to control the air temperature to within $\pm 1^{\circ} \mathrm{F}$ for mass flows up to $45 \mathrm{~kg} / \mathrm{s}$. The flow then enters the facility room and is then drawn into the plenum through a bank of flow straighteners which are contained between two mesh screens. The air passes through a specially designed bellmouth with a 10:1 area contraction. The turbulence levels at the bellmouth exit are expected to be less than 1 percent, and will be measured in the near future along with the impeller inlet turbulence profile. The flow then enters the compressor and exits through a specially designed throttle valve at the entrance to the collector. The throttle valve consists of two concentric rings with overlapping holes drilled in each ring which slide relative to each other to produce a throttle. This throttle valve design was chosen to minimize circumferential asymmetry in the exit static pressure distribution such as is typically found in scroll-type collectors. The bellmouth, inlet transition piece, and shroud flow path were machined together to minimize any boundary layer disturbance due to a step in the flow path. Altitude exhaust capability of $660 \mathrm{~mm}-\mathrm{Hg}(26 \mathrm{in}-\mathrm{Hg}$ ) of vacuum enables mass flow rates up to $45 \mathrm{~kg} / \mathrm{sec}$. A $1.115 \mathrm{MW}$ (1500-hp) electric motor and gear reducer drives the facility to a maximum speed of $2400 \mathrm{rpm}$. A complete description of the facility is provided by Wood et al. (1983).

\section{TEST COMPRESSOR}

During the design of the low speed compressor several conditions were imposed. First, the design should reflect the geometric and dynamic parameters that were deemed to be representative of modern compressors and second, the blade lean should not be so severe that laser access would be precluded. The design parameters for the low speed centrifugal compressor are given in table 1 while table 2 shows a comparison of some low speed centrifugal compressor stage parameters with those from several high speed centrifugal

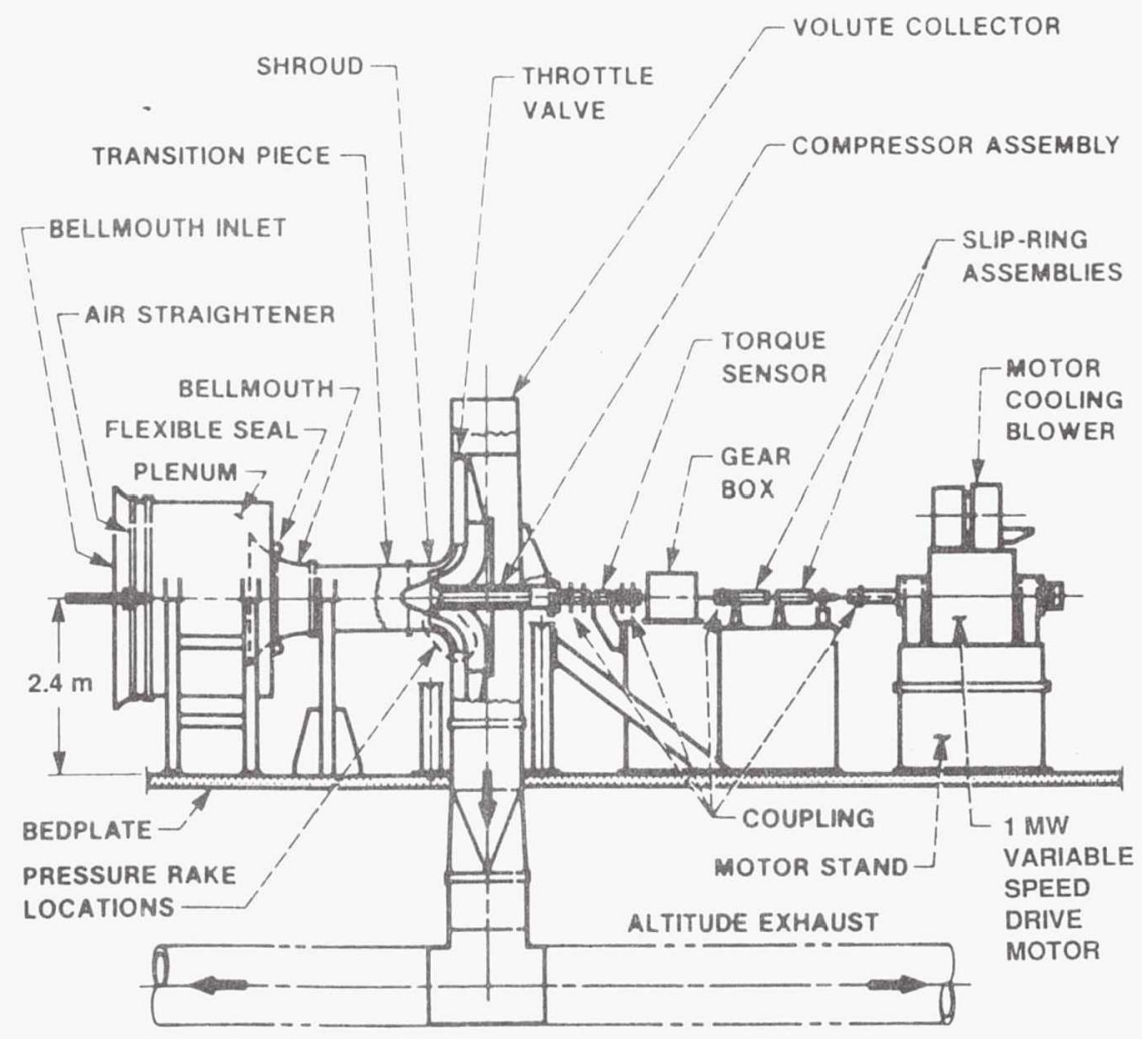

Figure 1 Low speed centrifugal compressor facility. 
Table 1 Design parameters for low speed centrifugal compressor

\begin{tabular}{lr|}
\hline Stage: & \\
Flow rate, kg/sec. & 30 \\
Total pressure ratio & 1.166 \\
Estimated efficiency & 0.90 \\
Rotor: & \\
Total pressure ratio & 1.173 \\
Estimated efficiency & 0.934 \\
Rotor speed & $1920^{1}$ \\
Inlet hub-tip radius ratio & 0.5 \\
Inlet span, cm & 22.042 \\
Inlet tip radius, cm & 42.939 \\
Exit radius, cm & 76.200 \\
Exit blade height, cm & 13.740 \\
Axial clearance, cm & $0.5725^{2}$ \\
Number of blades & 20 \\
Reynolds number, $U_{t} D_{t} / \nu_{0}$ & $16 \times 10^{6}$ \\
Inlet tip relative Mach number & 0.31 \\
Exit absolute Mach number & 0.29 \\
Diffuser: & \\
Rotor cxit/vane inlet radius ratio & \\
Number of vanes & 1.08 \\
Leading-edge circle radius, cm & 23 \\
Pressure surface angle, deg & 0.409 \\
Suction surface angle, deg & 72 \\
Channel divcrgence, deg & 80 \\
Area ratio & 7.65 \\
Throat blockage, percent & 2.9 \\
Throat Mach number & 2 \\
Exit Mach number & 0.263 \\
Inlet Reynolds number, $b_{t} V_{t} / \nu_{t}$ & 0.08 \\
& $10^{\circ}$ \\
\hline
\end{tabular}

compressor stages. Meridional hub and shroud contours for the rotor and a plan view of the stage geometry are shown in figure 2, along with the impeller blade angle and normal thickness distributions for the hub, midspan, and tip sections.

During the same time frame that the LSCC compressor was being designed, NASA Lewis embarked on a companion program to obtain detailed internal data on a high speed centrifugal compressor. Stage 2 in table 2 was selected as the candidate for the high speed tests since it has very high performance for a centrifugal compressor. Stage 2 was analyzed with a quasi 3-D inviscid program, with total pressure loss through rotor specified, in order to determine the level of loading used. A loading parameter representing the cross-channel pressure gradient divided by the mean flow dynamic head was used as a measure of the tendency of the hub wall boundary layer to migrate toward the blade suction surface. The design of the low speed centrifugal blading was set, using the above mentioned quasi 3-D code, so that a level of the loading parameter similar to that of Stage 2 would be obtained. At that time also, it was estimated that by the time the low speed compressor facility became operational, parabolic marching codes would be available for analysis with no capability to calculate impellers with splitter blades. Consequently, it was decided to design the initial impeller for less diffusion than might have been used otherwise in order to reduce the risk of streamwise separation, and with no splitter blades (although an even number of blades was selected for the impeller). This decision resulted in the absolute flow angle from the impeller being lower than the other stages as evidenced by the flow angles into the diffusers.

1 all testing was conducted at $1862.4 \mathrm{rpm}$ ( $97 \%$ design speed).

2 later reduced to $0.254 \mathrm{~cm}$.

Table 2 Comparison of low speed centrifugal compressor to typical centrifugal compressors.

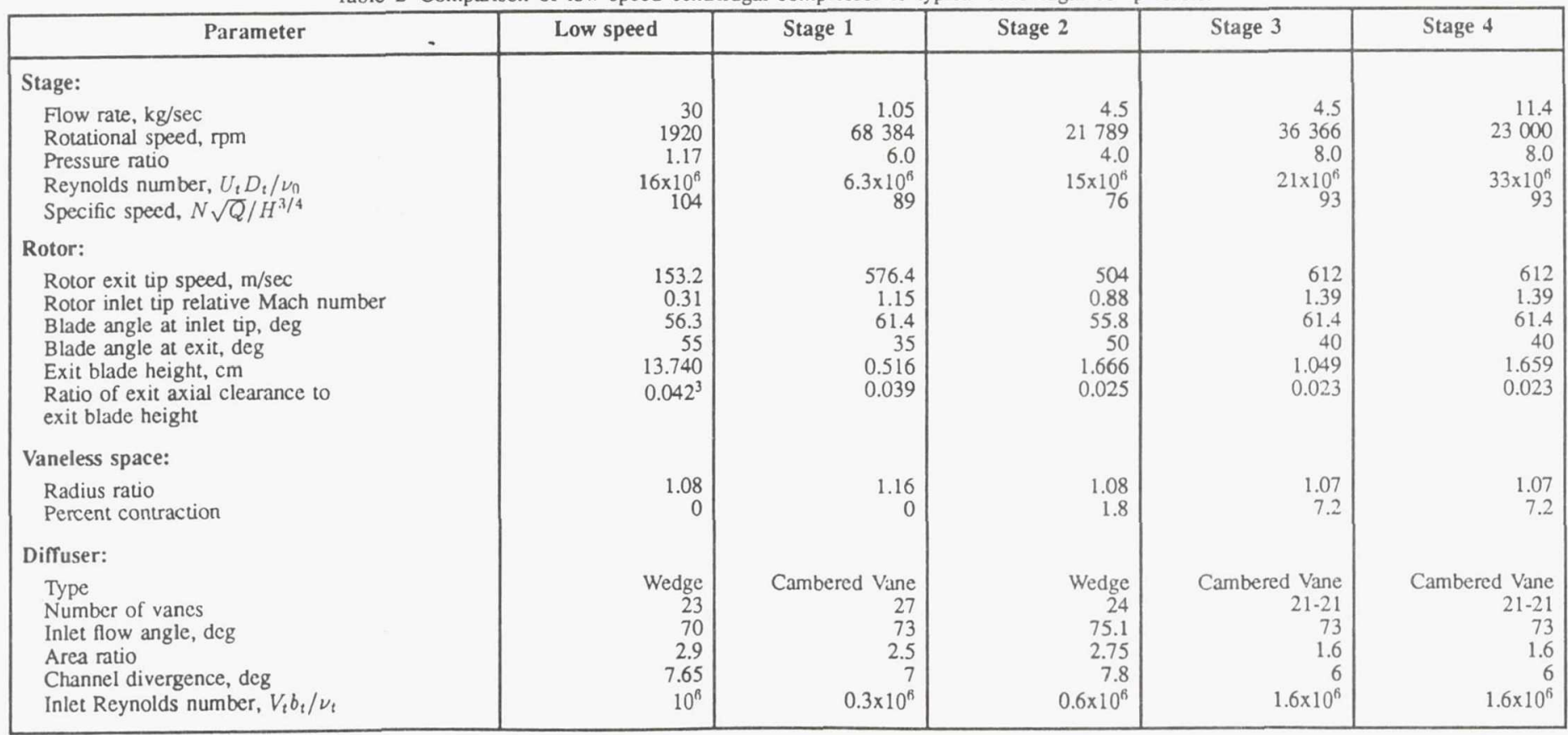

later reduced to 0.020 


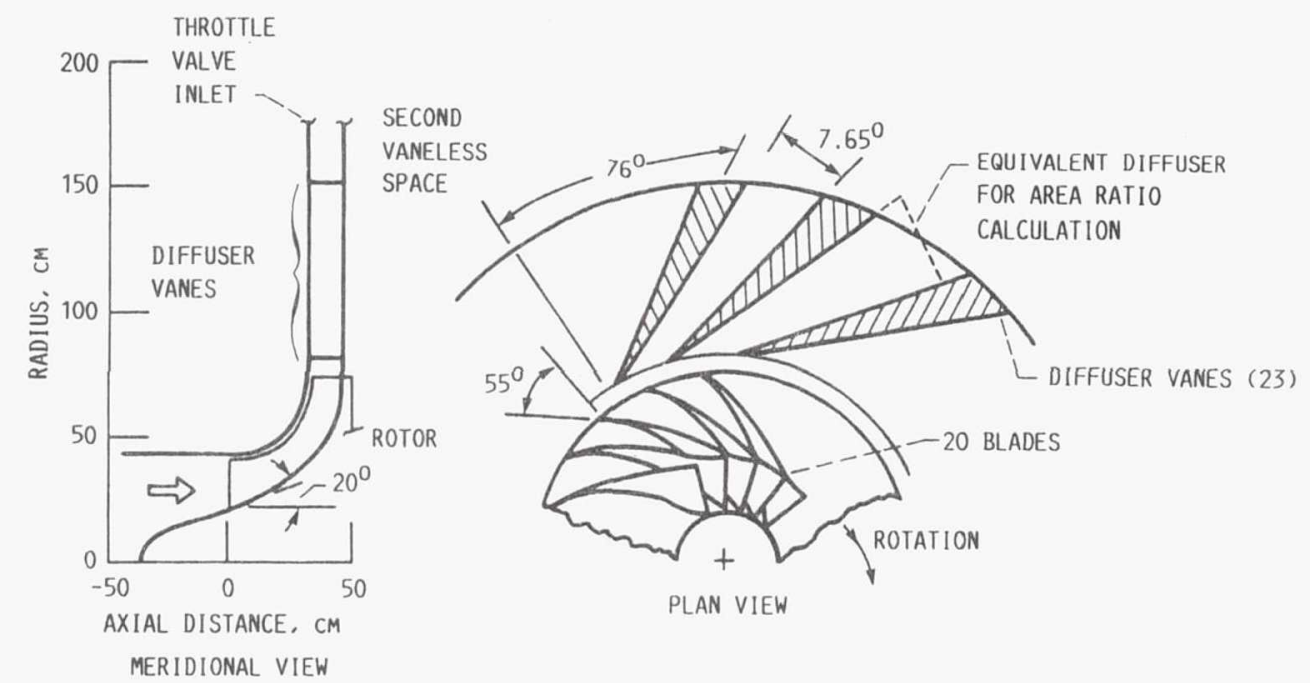

(a)
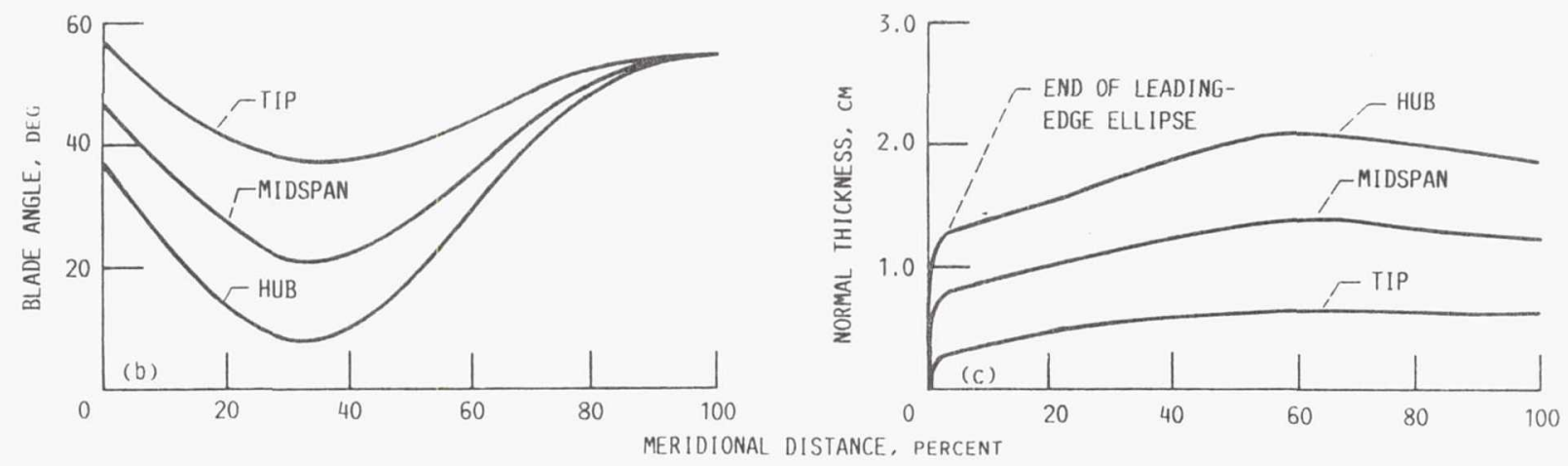

(a) MERIDIONAL AND PLAN VIEW.

(b) BLADE MEAN CAMBER LINE DISTRIBUTION FOR HUB, MIDSPAN, AND TIP.

(c) BLADE NORMAL THICKNESS DISTRIBUTION FOR HUB, MIDSPAN, AND TIP.

Figure 2 Configuration of low-specd centrifugal compressor initial stage design.

Although the virtues of the various types of diffusers used on centrifugal compressors - pipe, wedge, cambered vane - are extolled by various proponents, the area of basic interest is the region where the flow transitions from the somewhat axisymmetric impeller exit flow with potential perturbations from the diffuser vanes to a nearly one-dimensional flow in the diffuser channel downstream of the throat. Data obtained from the diffuser of a $4: 1$ pressure ratio centrifugal stage designed for automotive applications indicated that after the initial rapid adjustment of the flow around the uncovered region of the diffuser upstrearn of the throat, the isobars became nearly orthogonal to the diffuser channel mid-line. This same tendency was observed for the diffuser of Stage 1 at flow rates away from diffuser choke. The wedge diffuser of the LSCC is similar to that for Stage 2 and was designed with a throat area consistent with a pressure recovery coefficient from the impeller exit to the throat of 0.20 .

The choice of axial tip clearance reflected the previous experience obtained with small stages, such as Stage 1 in table 2 . The closest clearance tested with that stage was $3.9 \%$ of exit blade height which was $0.02 \mathrm{~cm}$. Also, since centrifugal stages tend to "flower" ( $i$ e., deflect axially) significantly with rotational speed, the actual running clearance at part-speed conditions can be much more than the design value. For example, for Stage 2 the design clearance was $2.5 \%$, but the clearance should be about $3.3 \%$ at $80 \%$ design speed - a speed that might be typical of a cruise condition - if the change in deflection with speed is considered. Stage 4 suffered even more axial deflection because of its higher design speed and even though it was tested at $2.4 \%$ clearance, the calculated value at $80 \%$ speed would be more like $6.1 \%$ clearance if active clearance control were not used. The choice of what clearance to use for the LSCC became a matter of selecting a low clearance representative of large machines or a rather large clearance more representative of small machines (and part speed conditions). Since it was anticipated that the duration of the test program would be long term, it was decided to provide for flexibility in varying tip clearance by selecting a large clearance for initial tests and reducing it for later tests. Obviously, adding material such as balsa wood to the impeller tips is preferable to machining a $1360 \mathrm{~kg}$ impeller. 


\section{INSTRUMENTATION}

The facility instrumentation includes a torque meter for measuring overall work input, and standard aerodynamic probes for surveying the distributions of total pressure and temperature as well as flow pitch and swirl angle at the impeller inlet and exit stations and diffuser exit station. Information on probe locations is given in figure 3 and table 3 . Five- hole pressure probes (figure 4) are used for the aerodynamic probe surveys. The probes are controlled by a PC-based automatic positioning system which is capable of simultaneous control of up to 16 drive motors (typically, 8 auto-yawing single-axis- positioning actuators).

Mass flow through the impeller is determined from a calibration curve of actual versus theoretical mass flows. The actual mass flow was obtained from detailed aerodynamic surveys of the bellmouth exit boundary layer. The theoretical mass flow rate is determined by averaging measurements from eight equally spaced static pressure taps around the circumference of the bellmouth throat and from the measured plenum total pressure and total temperature.

Figure 5 shows a schematic of instrumentation locations for the low speed centrifugal compressor. Arrays of static taps are provided on the impeller blade and hub surfaces, on the diffuser hub and vane surfaces, and along the shroud surface from impeller inlet to diffuser exit. Static taps are also provided at each of the probe survey stations. Five-element (spanwise) total pressure and temperature rakes (figure 6) are provided at the impeller inlet, knee, and exit regions. At each rake measurement plane the total pressure and temperature rakes can be positioned at three pitchwise locations. In addition, there are total pressure tubes at five spanwise locations along both the pressure and suction surfaces at each of the rake measurement planes. The total pressure rakes and surface mounted total pressure tubes provide a 25-element grid of total pressure measurements at the three rake measurement planes through the impeller. The total temperature rakes provide a 15 -element grid of

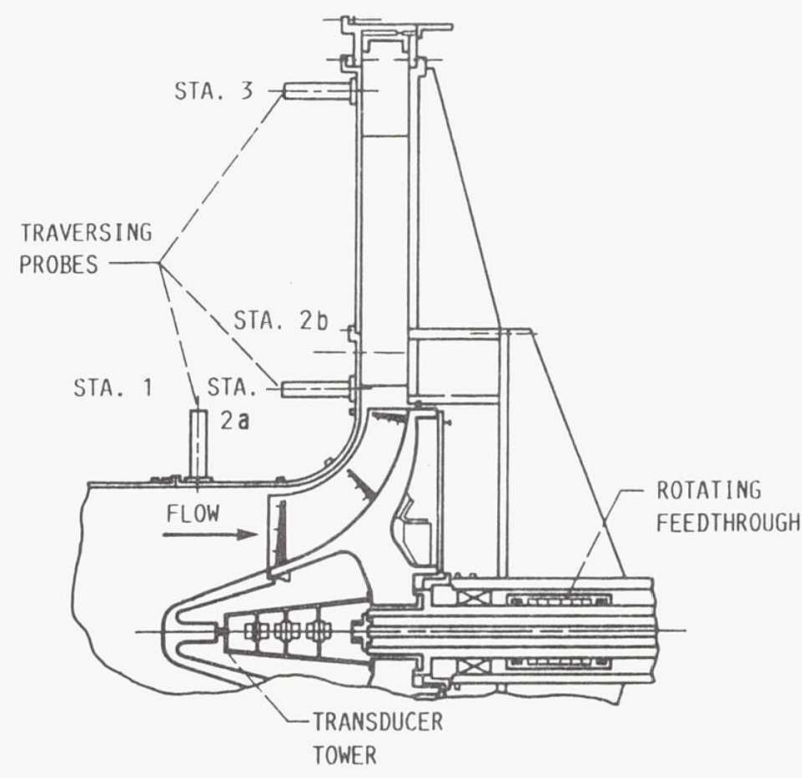

Figure 3 Schematic of LSCC flowpath. total temperature at each of the three measurement planes through the impeller. The rake and surface mounted total pressure tubes are oriented in the streamwise direction using the channel geometry for guidance and their openings are chamfered to improve flow angle insensitivity. Although all rakes can be installed at the same time, no more than one rake will be installed per blade channel for any measurement in order to minimize blockage effects and any disturbances produced on downstream elements.

All rotating frame pressures are sensed through 0.05 centimeter ( 0.020 inch) I.D. tubing by silicon pressure transducers housed in five 48-port electronic scanning pressure (ESP) modules. The ESP modules are mounted on the impeller centerline on an instrumentation tower located under the impeller nose cone (see figure 3). The transducer diaphrams within the ESP modules are oriented perpendicular to the centerline. The signals from the ESP modules are sent to the laboratory frame of reference via an electrical slip ring assembly. On-line calibration of the ESP modules is accomplished using a pneumatic slip ring which supplies calibration pressures to the ESP modules. The supplied calibration pressures are measured with a SETRA transducer which is also mounted on the instrumentation tower. The pressure tubing to the ESP modules is routed down the backface of the impeller between radial stiffening ribs. A flat plate bolted to these ribs traps a quantity of air approximately $7.6 \mathrm{~cm}$ (3 in) thick over the entire back face of the impeller, which essentially bathes the pressure tubing in air undergoing solid body rotation. Since this air is undergoing solid body rotation, it's possible to calculate the air temperature distribution and compare it with thermocouple readings located at various radii along the pressure tubing. The temperature

Table 3 Probe survey station locations.

\begin{tabular}{|c|c|c|}
\hline STATION & Z, cm & R, cm \\
\hline 0 & -76.581 & 0.0 to 43.511 \\
\hline 1 & -20.373 & 13.905 to 43.511 \\
\hline $2 \mathrm{a}$ & 32.205 to 46.543 & 81.280 \\
\hline $2 \mathrm{~b}$ & 32.205 to 46.543 & 95.872 \\
\hline 3 & 32.205 to 46.543 & 167.640 \\
\hline
\end{tabular}

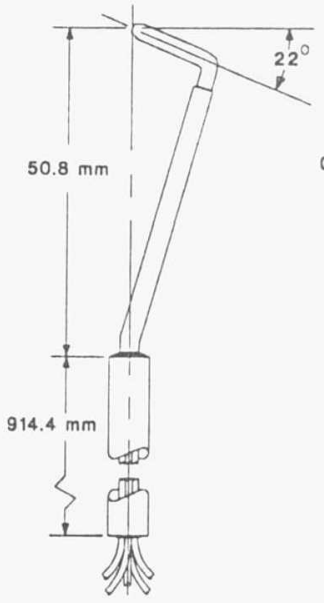

a) Inlet hub probe

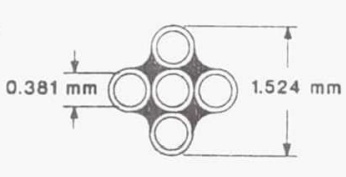

FRONT VIEW

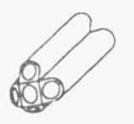

3/4 VIEW

b) Sensing head

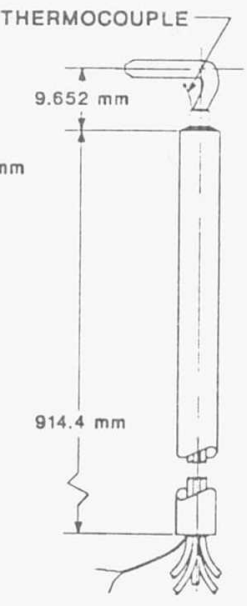

c) Inlet shroud an exit probe

Figure 4 Five-hole pressure probes. 


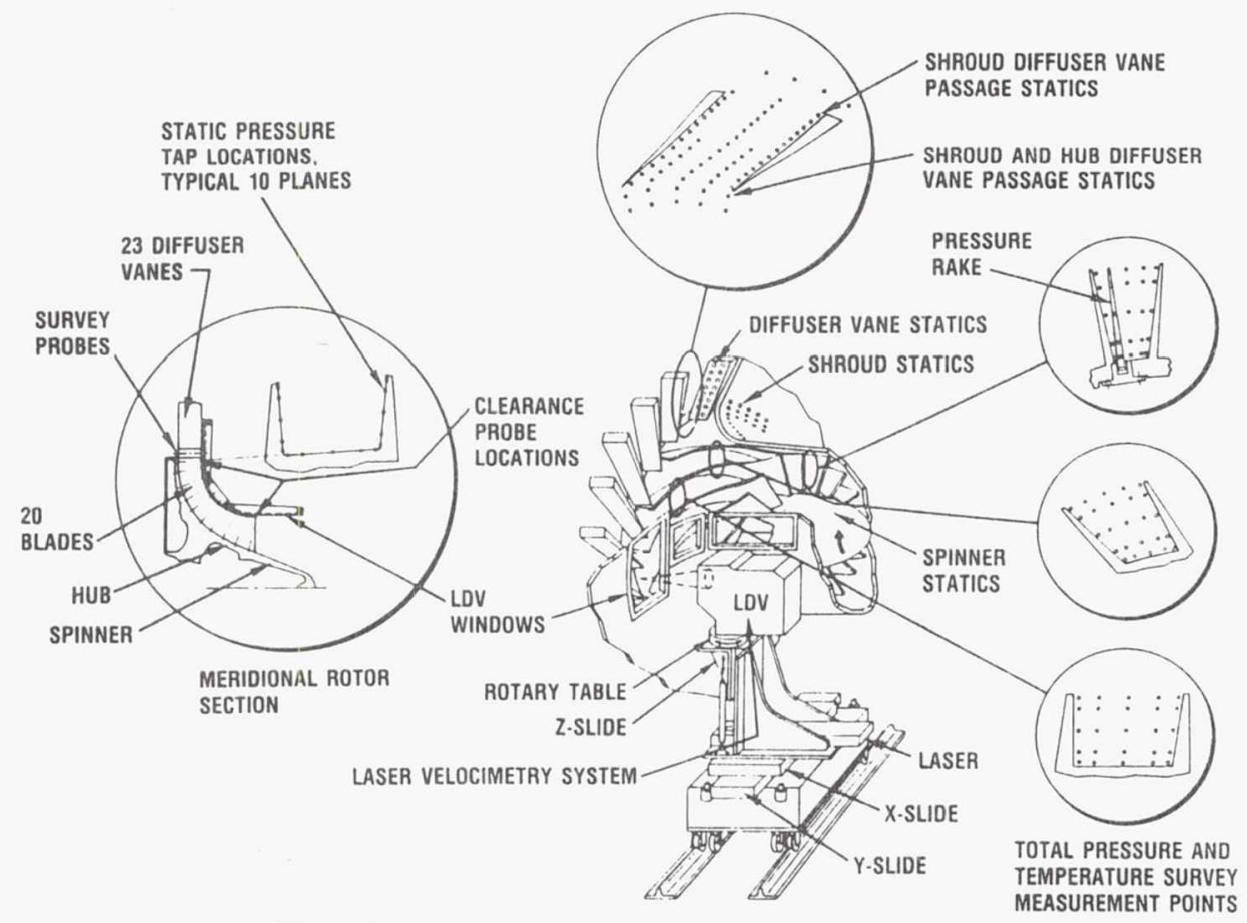

Figure 5 Low-speed centrifugal compressor instrumentation.

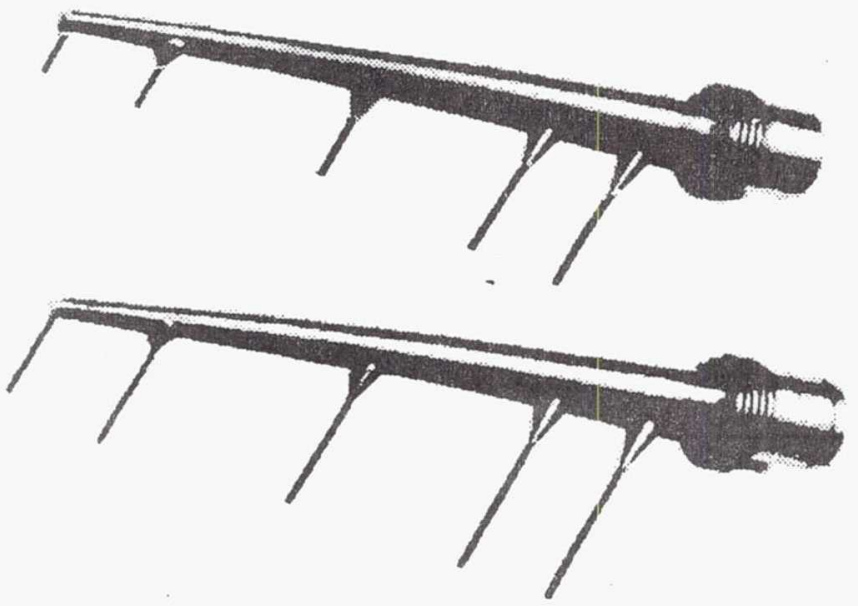

Figure 6 Rotating frame total pressure and total temperature rakes.

distribution along the pressure tubing is used to correct the measured pressures for the centrifugal head effects due to the fluid in the pressure tubing between the static pressure measurement location and the ESP pressure sensor port.

In addition to the above instrumentation, windows are provided over the impeller inlet, knee, and exit regions to allow for optical access to the flow field (figure 5). The exit window covers the rotor trailing edge, the vaneless space, and the diffuser throat region. Laser anemometry and flow visualization are therefore possible. The ammonia-ozalid flow visualization technique will be used in both the impeller and diffuser. Fluorescing oil, liquid crystal sheets, and tufts will also be used in the diffuser.

\section{MEASUREMENT UNCERTAINTIES}

Uncertainties determined for each of the primary and calculated measurements are listed in table 4 . In addition to providing uncertainty estimates for measured and calculated parameters, indications of the repeatability and circumferential uniformity of the flow field which can be expected from the low speed centrifugal compressor are provided. The repeatibility of the data provides assessment of how well flow conditions can be matched from test to test. The degree of circumferential uniformity of the flowfield is important since most steady-flow CFD codes require axisymmetric boundary conditions. The normalized velocity profiles shown in figures 7 and 8 were acquired at four different circumferential locations over a one month period. These results therefore provide an indication of the repeatability of the measurements as well as the degree of circumferential uniformity in the impeller inlet and exit flow field.

Table 4 Measurement uncertainties ( $95 \%$ confidence interval).

\begin{tabular}{|l|c|c|}
\hline \multicolumn{1}{|c|}{$\begin{array}{c}\text { Primary } \\
\text { measurement }\end{array}$} & $\begin{array}{c}\text { Nominal } \\
\text { value }\end{array}$ & $\begin{array}{c}\text { Percent } \\
\text { uncertainty }\end{array}$ \\
\hline Pressure & $101325 \mathrm{~N} / \mathrm{m}^{2}$ & 0.034 \\
Temperature & $288^{\circ} \mathrm{K}$ & 0.4 \\
Swirl angle & $70 \mathrm{deg}$ & 1.4 \\
Pitch angle & $5 \mathrm{deg}$ & 3.0 \\
Position & $13 \mathrm{~cm}$ & 0.05 \\
\hline \multicolumn{1}{|c|}{ Calculated } & Nominal & Percent \\
measurement & value & uncertainty \\
\hline Velocity & $100 \mathrm{~m} / \mathrm{sec}$ & 0.25 \\
Mass flow rate & $30 \mathrm{~kg} / \mathrm{sec}$ & 0.3 \\
Pressure ratio & 1.13 & 0.042 \\
\hline
\end{tabular}




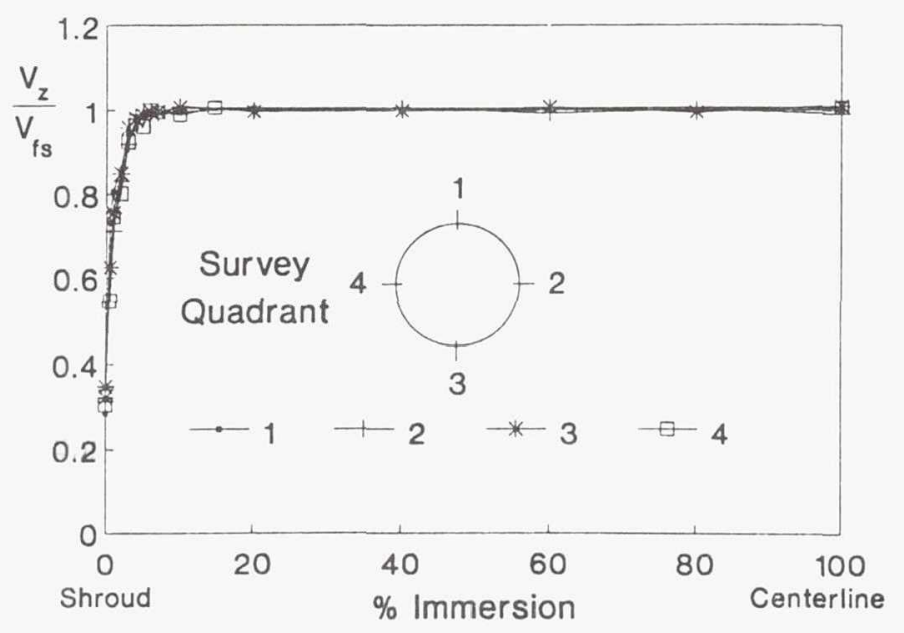

Figure 7 Circumferential uniformity/repeatability of inlet flow field, Station 0.

\section{RESULTS AND DISCUSSION}

The data presented herein consist of conventional aerodynamic probe surveys upstream and downstream of the impeller, and flow visualization results from fluorescing oil (Jurkovich et al., 1984). Results of computational analyses which support the experimental data are also presented. The main emphasis of the data and computational analysis presented herein is to illustrate the impact of synergism between experiments and computational analysis on the development of the low speed centrifugal compressor facility.

Research operating conditions selected for detailed investigations of the low speed centrifugal compressor flow field were chosen to reflect design flow conditions $(30 \mathrm{~kg} / \mathrm{sec})$ as well as high $(36.36 \mathrm{~kg} / \mathrm{sec})$ and low $(23.64 \mathrm{~kg} / \mathrm{sec})$ flow conditions. Because of a problem with the facility temperature control, that has since been fixed, and limitations on the maximum physical speed of the impeller (1950 rpm), the corrected speed for all research data was set at $97 \%$ of design speed (1862.4 rpm). Preliminary measurements indicate that the impeller inlet boundary layer thickness measured at survey station 1 is approximately $20 \%$ of span $(5.921 \mathrm{~cm})$ on the shroud and $2 \%$ of span $(0.592 \mathrm{~cm})$ on the hub.

\section{Impact of Experiment/CFD Synergism}

The history of the development of the low speed centrifugal compressor illustrates how synergism between computational analyses and experimentation has affected the final design of the test hardware. The first research entry into the facility occurred October 1, 1988, and due to a scheduled rehabilitation of the NASA variable-frequency control facilities, testing was concluded November 1,1988 . Since this was a new facility, the intent of the initial entry was to check out the research data acquisition system. During the one month of operation preliminary surveys were acquired upstream and downstream of the impeller. The data were not analyzed in great detail, since the probes were uncalibrated and because several problems were uncovered with the data acquisition system.

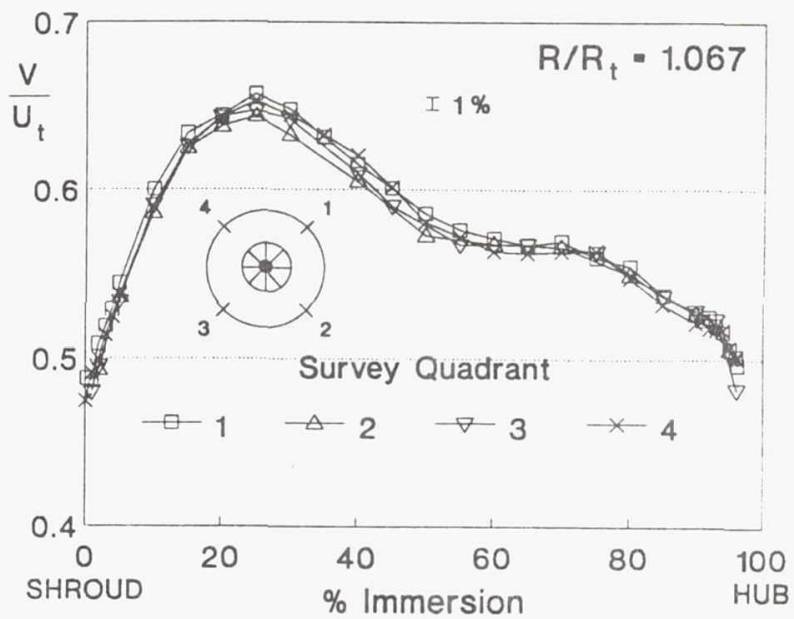

Figure 8 Circumferential uniformity/repeatibility of impeller exit flow field, Station $2 \mathrm{a}$ ( $4 \%$ tip clearance).

About the same period of time, results of a computational analysis of the compressor flow field by Moore and Moore $(1989,1990)$ of the Virginia Polytechnic Institute became available under a NASA grant. This grant was initiated in the spirit of a cooperative effort to minimize the time typically required to develop a new facility. The Moore's calculated the LSCC flow field with their Elliptic Flow Program, a 3-D pressure correction solution for discretized forms of the Navier-Stokes equations. The 3-D flow through the impeller was modelled using a 53 streamwise by 22 spanwise by 21 pitchwise grid.

The Moore's CFD solution indicated separation along the impeller shroud wall near the impeller exit as shown in figure 9. This separation continued downstream all the way to the outflow boundary condition which prevented the CFD solution from converging since the backflow within the separation region was bringing mass flow into the solution domain across the out-flow boundary. In order to obtain a converged solution, the Moore's altered the geometry in the vaneless diffuser region, as shown in figure 10 , to force the separated flow region to close before it reached the outflow boundary.

About the same time the Moore's were generating their predictions of the LSCC flow field, NASA was also generating predictions of the flow field using the 3-D computational analyses of Hah $(1988,1989)$ and Dawes (1988). These predictions also indicated that separation would occur along the impeller shroud. As a result of these CFD predictions, the previously acquired preliminary experimental results were investigated and were found to indicate a severely retarded flow region near the shroud wall as shown in figure 11. Although the preliminary measurements were inconclusive in substantiating the predicted shroud wall separation, the severely retarded flow region measured near the shroud wall indicated that shroud wall separation was probably imminent. Certainly, a reverse flow region within the tip clearance gap is expected, although the survey probe was not able to detect it. Since the rig was intended for fundamental flow physics research and CFD assessment, it was considered undesirable to have separation which would affect the impeller flow field and produce an undesirable downstream boundary condition for CFD analysis. Considering that the facility was 


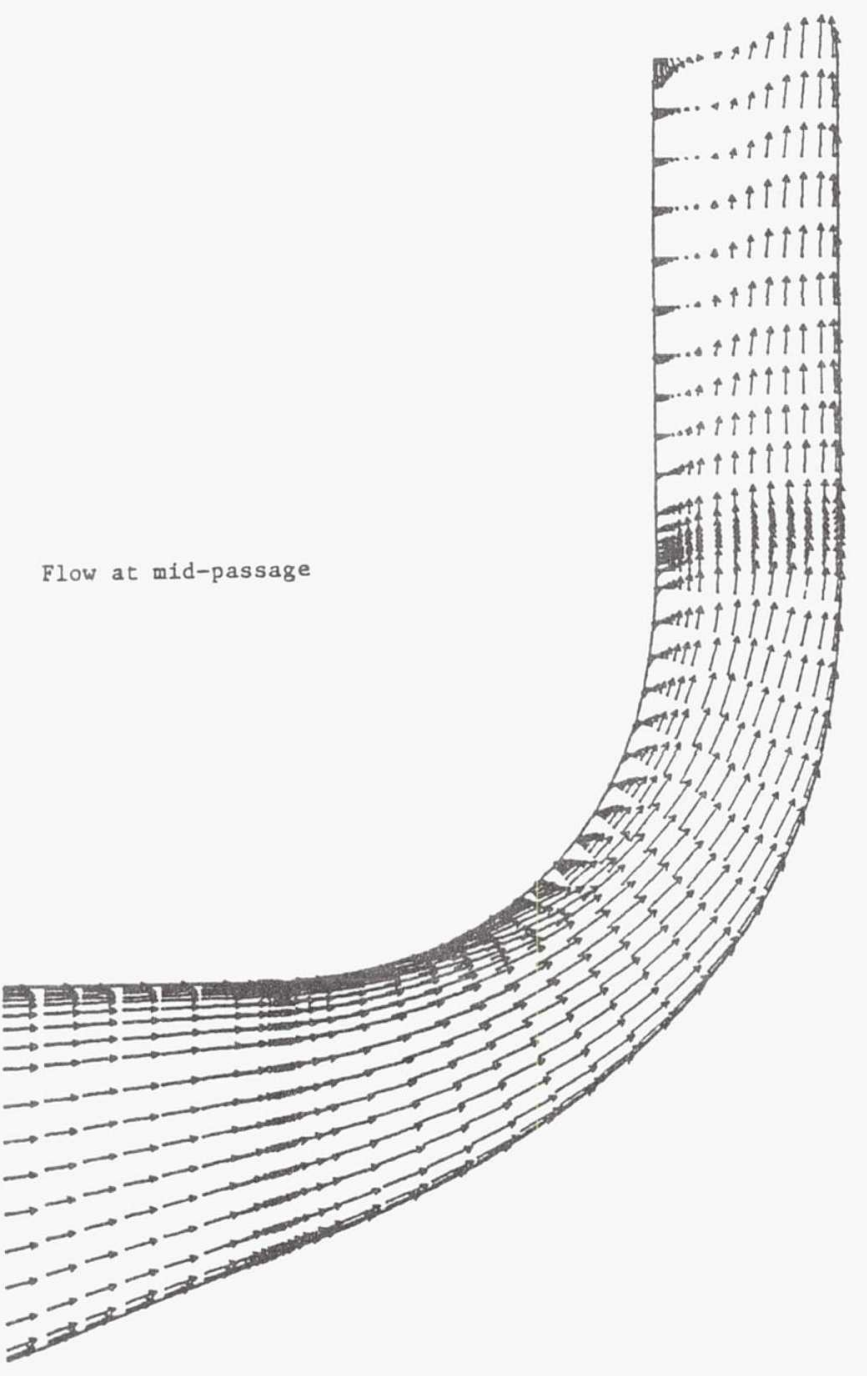

Figure 9 Meridional view of velocity vectors from Moore's (1988) 3-D flow calculations of LSCC with $4 \%$ tip clearance and constant height vaneless diffuser.

shutdown for a scheduled one year rehabilitation on November 1 , 1988 , further investigation of the predicted shroud wall separation until after the shutdown was not possible. We decided therefore, that the best time to effect any modifications to the compressor geometry would be during the facility shutdown.

Two potential modifications to the low speed centrifugal compressor were considered; 1) reduce the impeller exit tip clearance, 2) increase the vaneless diffuser area contraction. Reduction of the impeller tip clearance was considered appropriate since the low speed centrifugal compressor was initially designed with a uniform $4 \%$ exit tip clearance which, although not atypical of industry practice (see table 2 ), was on the high side. Before reducing the tip clearance, we asked industry for an opinion as to what level of tip clearance would be most representative of typical operating conditions. Based on industry response, we reduced the tip clearance to a circumferentially uniform level from inlet to exit of $2 \%$ based on the impeller exit blade span by bonding balsa wood strips to the tip of the impeller. In-house CFD analysis of the low speed centrifugal compressor with

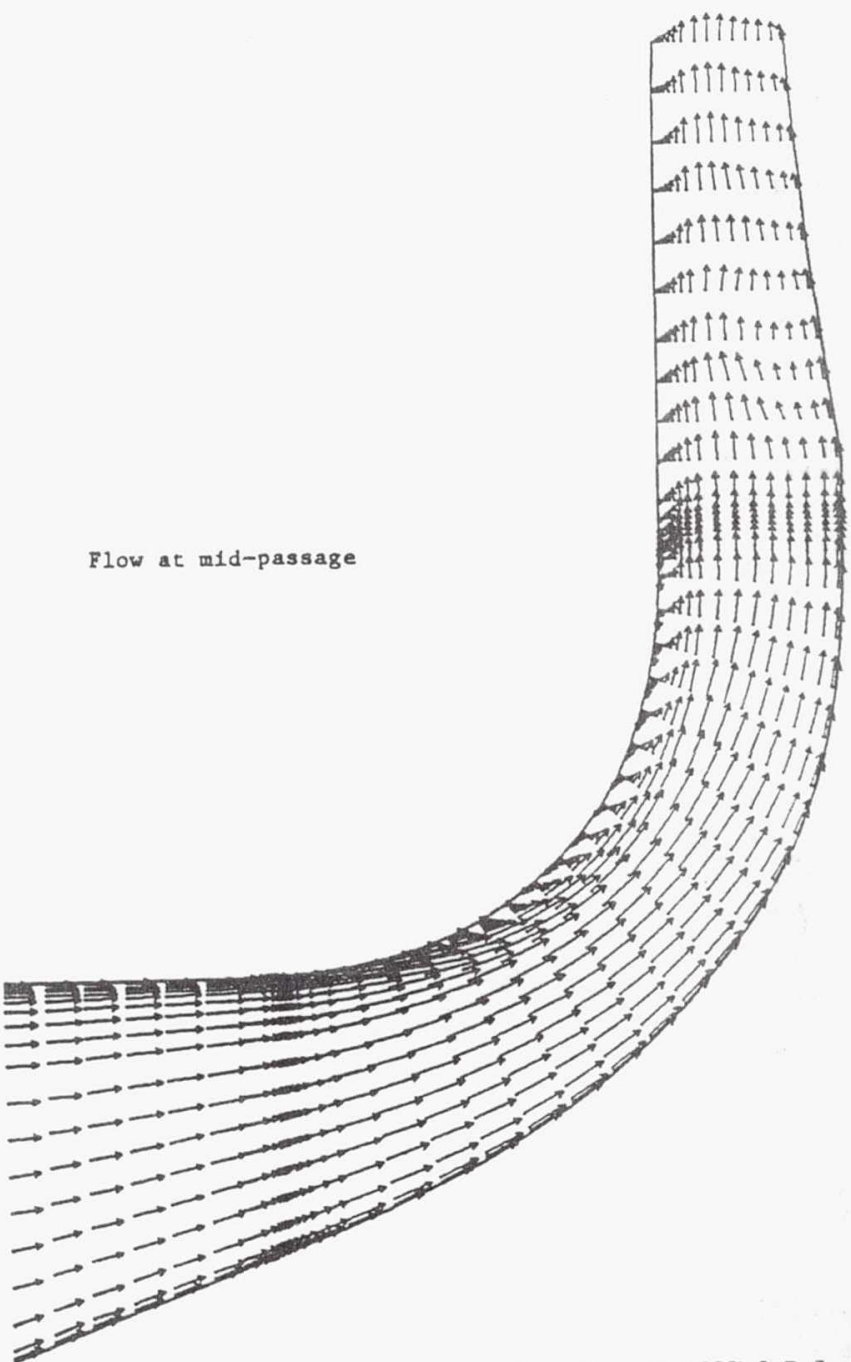

(1988) 3-D flow Figure 10 Meridional vicw of velocity vectors from Moore's
calculations of LSCC with $4 \%$ tip clearance and modified vaneless diffuser.

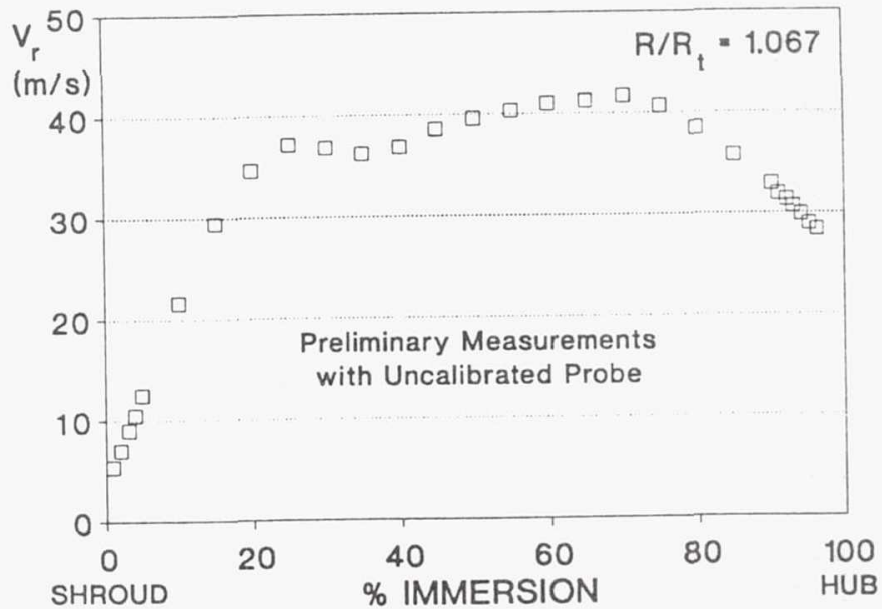

Figure 11 Radial velocity distribution at impeller exit station $2 \mathrm{a}$ ( $4 \%$ tip clearance) 

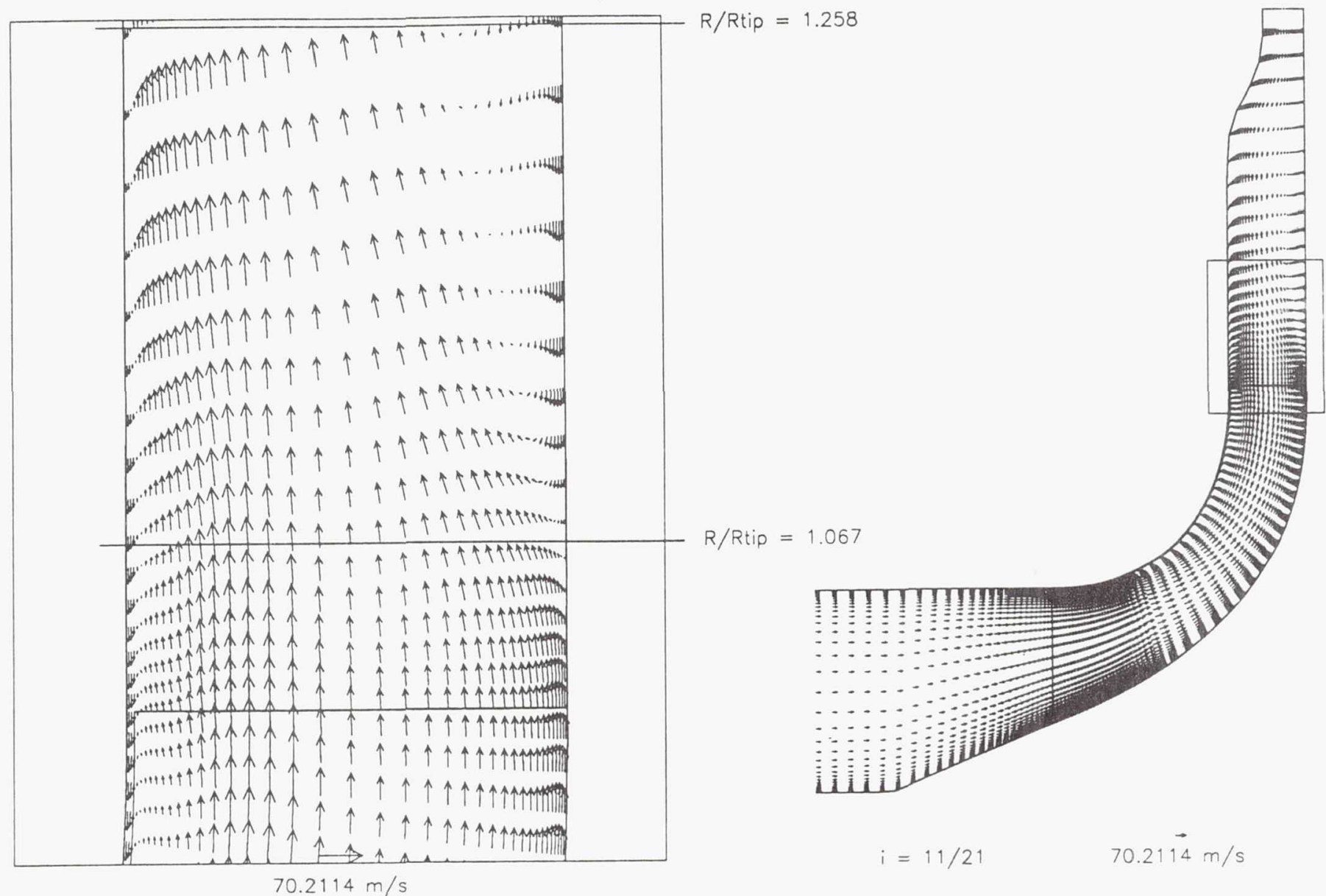

Figure 12 Meridional view of velocity vectors predicted by the Dawes 3-D viscous flow calculation of the LSCC with $2 \%$ tip clearance.

the reduced tip clearance was then initiated using the Dawes and Hah codes to determine if a further modification to increase the vaneless diffuser area contraction was necessary. At the same time the low speed centrifugal compressor was reinstalled in the facility and testing was initiated with the reduced tip clearance impeller. Hereafter, all references to the low speed centrifugal compressor will be for the reduced tip clearance impeller.

Figure 12 shows a meridional view of velocity vectors at midpitch predicted by the Dawes code. The Dawes code was run with a 107 streamwise by 41 spanwise by 21 pitchwise grid with 3 control volumes in the clearance gap. The Dawes solution predicts separation to occur on both the shroud and hub walls. A comparison between the predicted and measured radial velocity profiles at the impeller exit survey station, STA. $2 \mathrm{a}$, is shown in figure 13. The experimental results clearly do not indicate separation on either the hub or shroud surfaces as is predicted by the Dawes code. Since the Dawes code prediction showed that the hub separation began very close to the experimental survey station and that the shroud separation was confined to a thin layer, it seemed reasonable to expect that the survey probe might not be able to detect the separation regions. As a result, it was decided to add a new aerodynamic survey location, STA. $2 b$, near the point at which the hub wall separation was predicted to reach it's maximum thickness ( $i$ e., at $R / R_{t}=$ $1.258)$. In addition, flow tufts were taped to the laser window

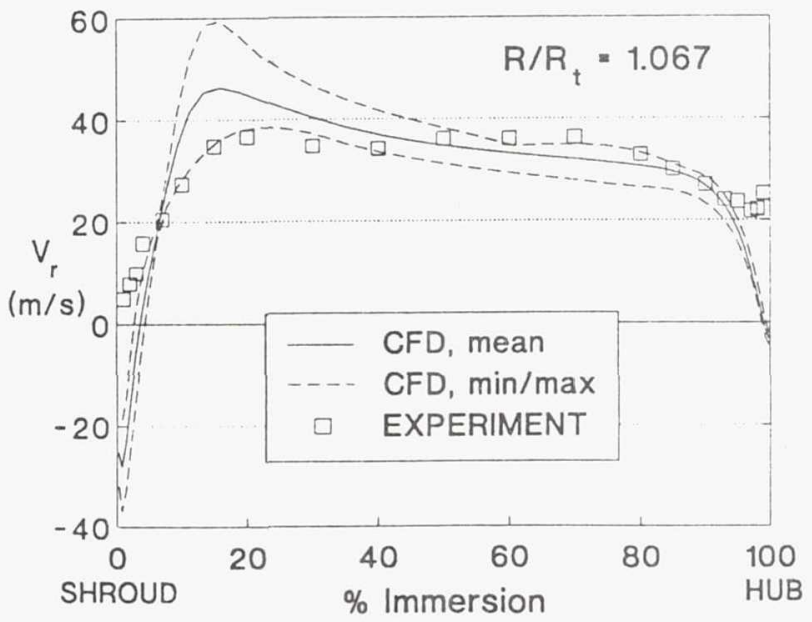

Figure 13 Radial velocity distribution at impeller exit station $2 \mathrm{a}$ ( $2 \%$ tip clearance). 
covering the impeller/diffuser shroud region and to the opposite hub diffuser wall. The shroud tufts indicated that the reduced impeller tip clearance was effective in clearing up the separation on the impeller exit shroud region. However, the inner wall tufts on the hub side of the diffuser indicated that the flow was now separated beyond impeller exit survey station $2 a$, as predicted by the Dawes code. The shroud wall flow separation due to the $4 \%$ tip clearance may have produced sufficient flow blockage to prevent separation on the hub wall. Cleaning up the flow separation on the shroud wall reduced the shroud side blockage which resulted in subsequent separation of the hub wall. The propensity for hub wall separation is a result of rapid deceleration of the flow near the hub wall as flow in the relative frame of reference leaving the impeller is brought to rest at the stationary hub wall. A comparison between the Dawes code predictions and measured radial velocity profiles at impeller exit survey station $2 \mathrm{~b}$ is shown in figure 14 . The experimental results clearly indicate a flow separation on the hub wall and show no indication of separation on the shroud wall which is in agreement with the flow tufts. Another flow visualization technique using fluorescing oil was also used to indicate flow directions on the shroud and hub surfaces at the impeller exit. The fluorescing oil technique substantiated the results of the flow tufts and the flow surveys, indicating separation on the hub wall and elimination of separation on the shroud wall, see figures 15 and 16 .

The Dawes CFD solution predicts the onset of separation on the hub wall quite well but over predicts the spanwise extent of the separation region. However, both CFD predictions and experimental flow visualization indicate that flow along the hub wall is separating. Since the low speed centrifugal compressor is intended for fundamental flow physics investigation and CFD code assessment, the facility was therefore modified by installing a hub wall contour in order to increase the vaneless diffuser area contraction and thereby eliminate the hub wall separation. The vaneless space between the impeller exit and vaned diffuser leading edge will also be contracted for the LSCC tests with the vaned diffuser installed in order to reduce the propensity for the flow to separate. The modified hub wall contour for the current vaneless diffuser configuration is shown in figure 17. It should be mentioned that the shroud wedge, also shown in figure 17 , has been present since the initial vaneless diffuser configuration in order to reduce the flow area beyond the laser window. The shroud wedge blockage alone, however, was insufficient to prevent flow separation.

The new hub contour has been analyzed using the Dawes code. The predicted results indicate that the flow is still separated on the shroud. This separation starts near mid-chord and continues out into the diffuser. The shroud separation closes before the outflow boundary is reached, however, as shown in figure 18. There is no separation on the hub wall for flow rates which correspond to the design flow rate or higher. At flow rates near $75 \%$ of design flow rate or lower a small separation bubble occurs on the hub wall, but this bubble closes before reaching the outflow boundary condition. In order to enable assessment of the ability of CFD codes to capture changes in the flow field as the compressor operating condition is changed, data will be acquired for flow rates with and without flow separation on the diffuser hub wall.

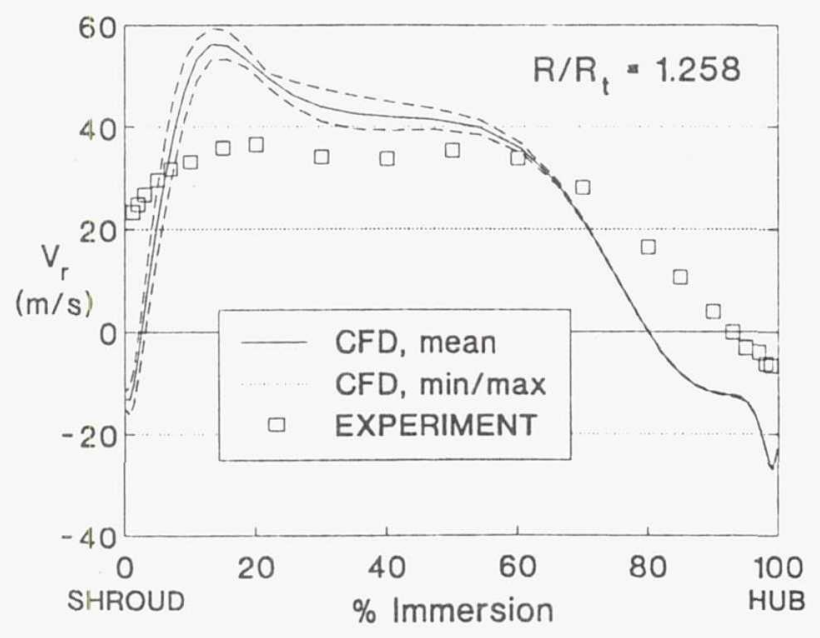

Figure 14 Radial velocity distribution at impeller exit station $2 b$ ( $2 \%$ tip clearance). 


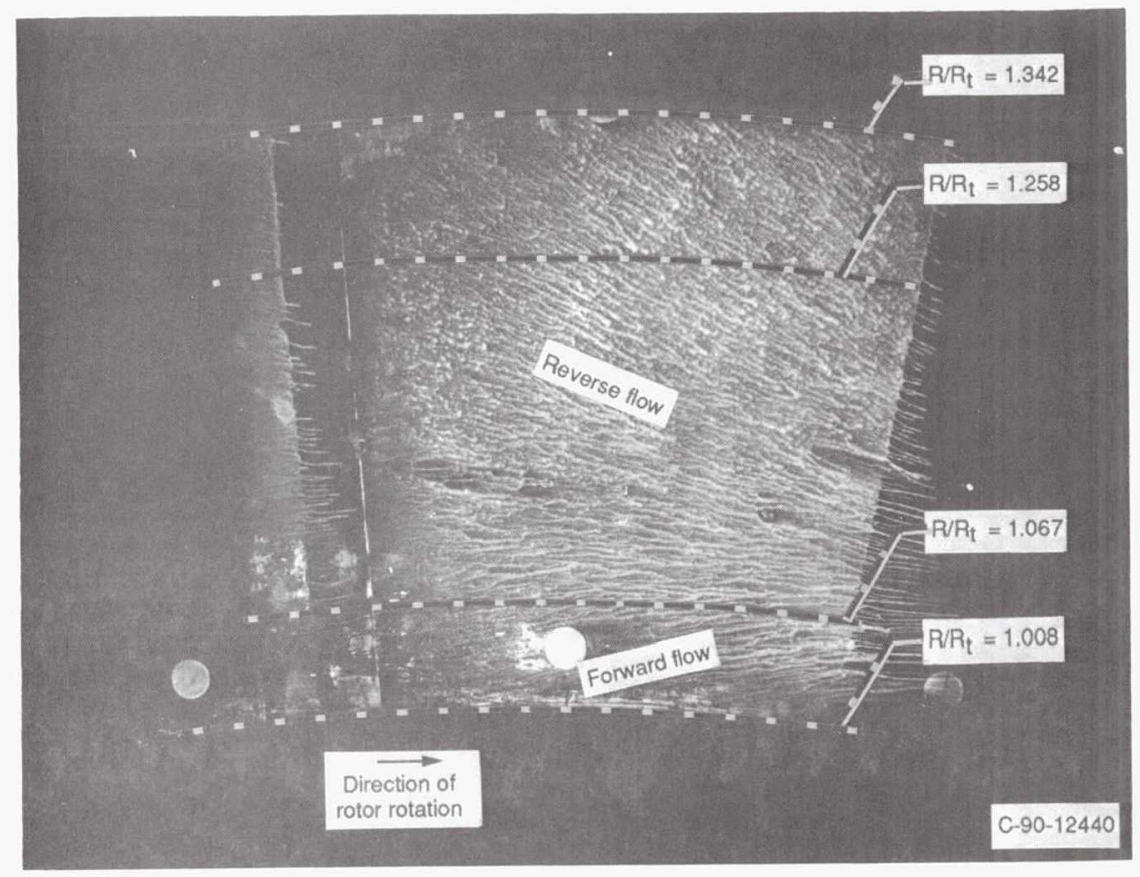

Figure 15 Fluorescing oil flow visualization on hub surface (2\% tip clearance).

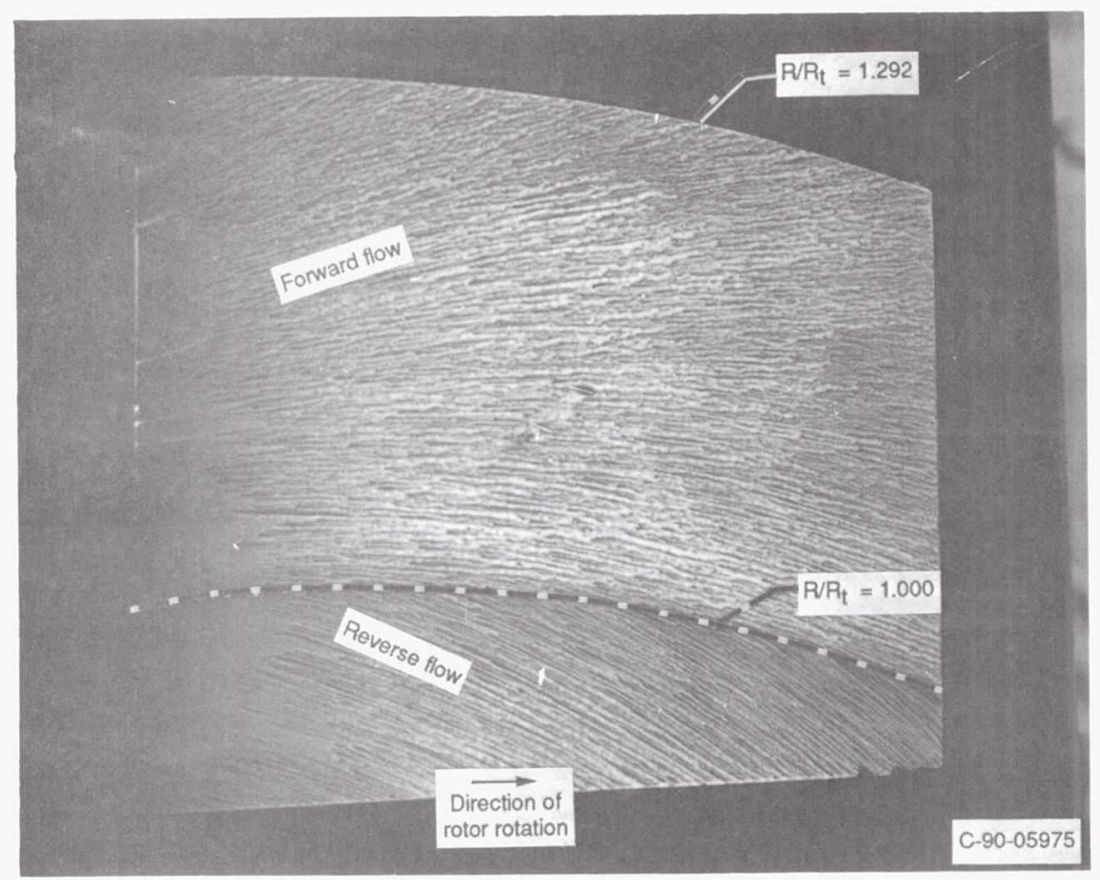

Figure 16 Fluorescing oil flow visualization on shroud surface (2\% tip clearance). 


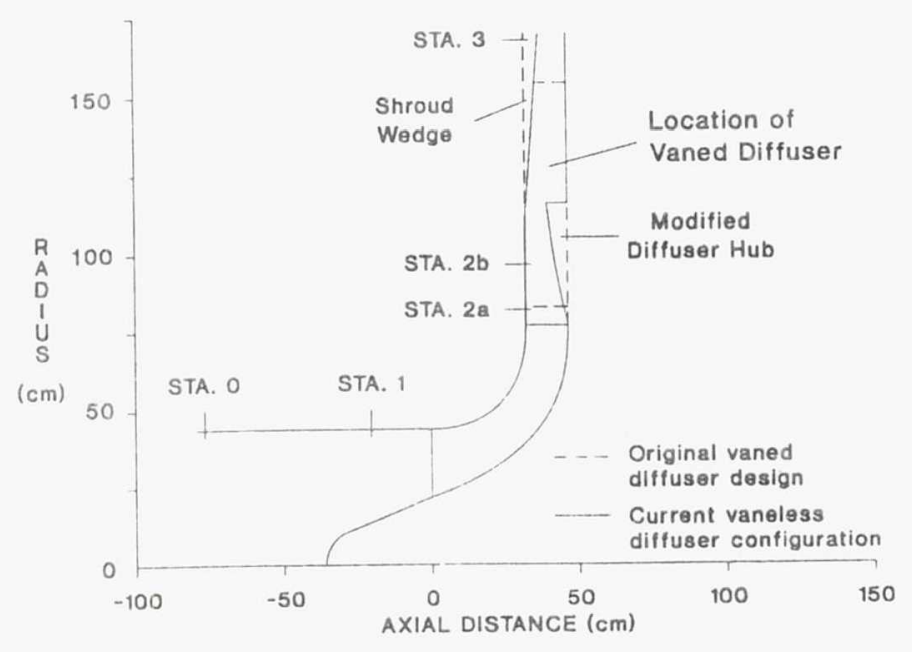

Figurc 17 Final flow path configuration showing modification to diffuser hub contour in order to climinate separation.

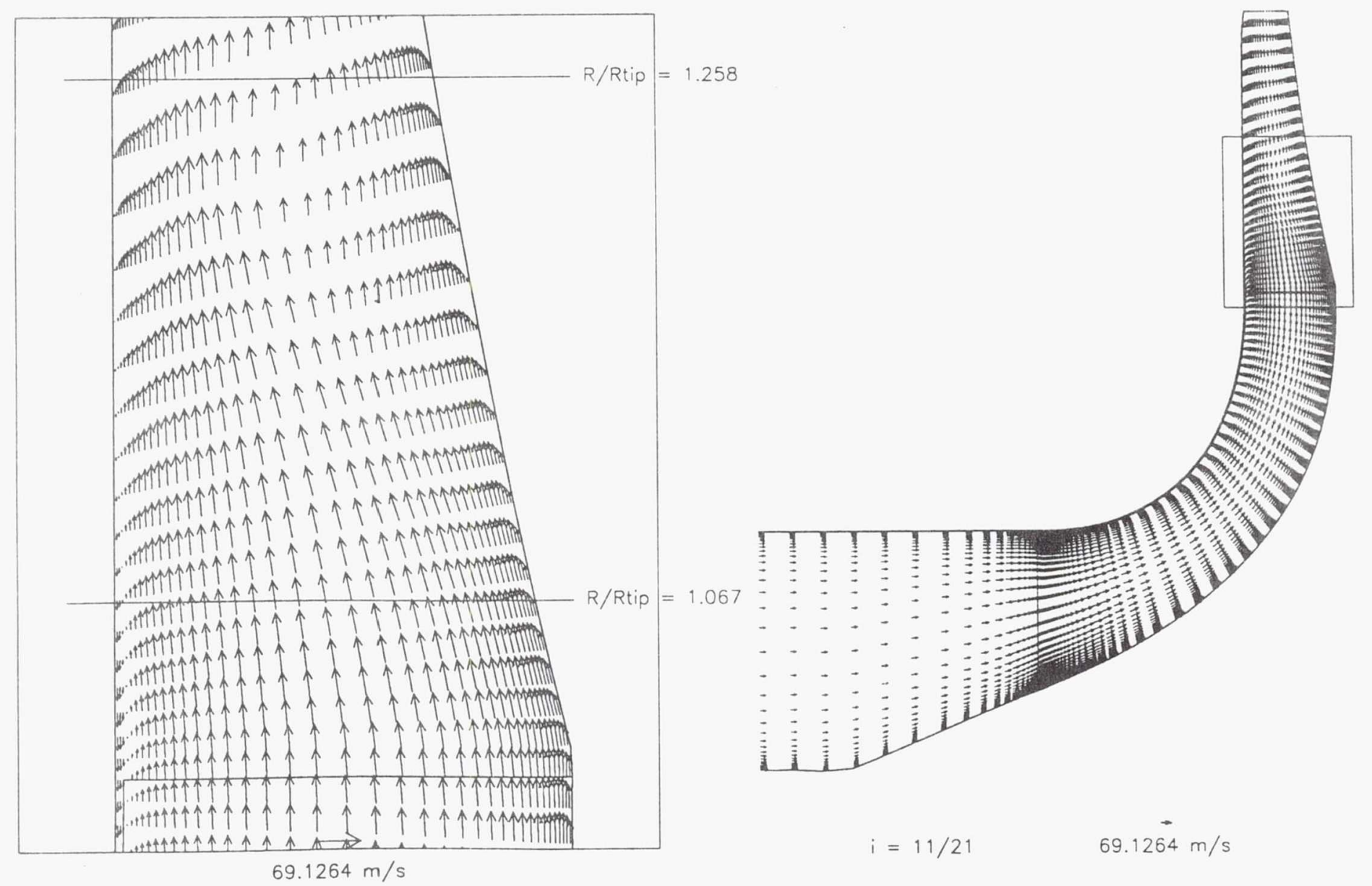

Figure 18 Final solution of LSCC velocity field with modified diffuser hub contour and $2 \%$ tip clearance as predicted by Dawes $3-D$ viscous code. 


\section{SUMMARY AND CONCLUSIONS}

A new low speed centrifugal compressor facility for 3-D viscous code assessment and fundamental flow physics research has been described. The facility is heavily instrumented with pressure and temperature probes, both in the rotating and stationary frames of reference, and has provisions for flow visualization and laser velocimetry. Preliminary measurements presented herein indicate the high quality of the data which can be expected from this facility.

The synergism between experimental data and computational analysis during the development of the LSCC has led to modifications of compressor geometry which facilitate its use for fundamental flow physics research and computational code assessment. Although the CFD models used for analysis of the LSCC flow field may not have correctly predicted the magnitudes of the flow parameters, they have been invaluable for capturing the essential features of the flow physics. The CFD results also provided useful guidance for the experimental efforts to validate the CFD predictions.

\section{ACKNOWLEDGMENTS}

The authors would like to thank C. Hah and K. Kirtley for their computational analyses and T. Strazisar for his helpful suggestions and assistance in preparing this paper.

\section{REFERENCES}

Dawes, W. N., 1988, "Development of a 3-D Navier Stokes Solver of Application to all Types of Turbomachinery," ASME Paper 88-GT-70.

Dorney, D. J. and Davis, R. L., 1990, "Centrifugal Compressor Impeller Aerodynamics (A Numerical Investigation)," ASME Paper 90-GT-213.

Eckardt, D., 1976, "Detailed Flow_Investigations within a HighSpeed Centrifugal Compressor Impeller," Transactions of the ASME, Journal of Fluid Engineering, Vol. 98, No. 3, pp. 390-402.

Hah, C., Bryans, A. C., Moussa, Z. and Tomsho, M. E., 1988, "Application of Viscous Flow Computations for the Aerodynamic Performance of a Back-Swept Impeller at Various Operating Conditions," Transactions of the ASME, Journal of Turbomachinery, Vol. 110, pp. 303-310.

Hah, C. and Krain, H., 1989, "Secondary Flows and Vortex Motion in a High Efficiency Backswept Impeller at Design and OffDesign Conditions," Transactions of the ASME, Journal of Turbomachinery, Vol. 112, No. 1, pp. 7-13.
Hayami, H., Senoo, Y. and Ueki, H., 1984, "Flow in the Inducer of a Centrifugal Compressor Measured with a Laser Velocimeter," ASME Paper 84-GT-74.

Japiske, D. and Karon, D. M., 1989, "Laser Transit Anemometry Investigation of a High Speed Centrifugal Compressor," ASME Paper 89-GT-155.

Johnson, M. W. and Moore, J., 1980, "The Development of Wake Flow in a Centrifugal Impeller," Transactions of the ASME, Journal of Engineering for Power, Vol. 102, No. 2, April, 1980.

Johnson, M. W. and Moore, J., 1983, "Secondary Flow Mixing Losses in a Centrifugal Impeller," Transactions of the ASME, Journal of Engineering for Power, Vol. 105, No. 1, January, 1983.

Joslyn, H. D., Brasz, J. J., and Dring, R. P., 1990, "Centrifugal Compressor Impeller Aerodynamics (an Experimental Investigation)," ASME Paper 90-GT-128.

Jurkovich, M. S., Greber, I., Hingst, W. R., "Flow Visualization Studies of a 3-D Shock/Boundary Layer Interaction in the Presence of a Non-Uniform Approach Boundary Layer," AIAA Paper 84-1560.

Krain, H. and Hoffman, W., 1989, "Verification of an Impeller Design by Laser Measurements and 3D-Viscous Calculations," ASME Paper 89-GT-159.

Moore, J. and Moore, J. G., 1989, “A Prediction of 3-D Viscous Flow and Performance of the NASA Low-Speed Centrifugal Compressor," Virginia Polytechnic Institute and State University, Mechanical Engineering Department, Turbomachinery Research Group, Report No. JM/89-1, January 1989.

Moore, J. and Moore, J. G., 1990, "A Prediction of 3-D Viscous Flow and Performance of the NASA Low-Speed Centrifugal Compressor," ASME Paper 90-GT-234.

Wood, J. R., Adam, P. W. and Buggele, A. E., 1983 "NASA Low-Speed Centrifugal Compressor For Fundamental Research," NASA TM 83398.

Young, M. Y., Spraker, W. A., and Struble, A. G., 1987, "Laser (L2F) Measurements at the Impeller Inlet and Tip Exit of a $91 \mathrm{~mm}$ Turbocharger Compressor," Third International Symposium on Laser Anemometry, ASME New York, 1987. 
NNS^

National Aeronautics and

Space Administration

Report Documentation Page

$\begin{array}{ll}\text { 1. Report No. } & \text { NASA TM-103710 } \\ & \text { AVSCOM TR } 91-\mathrm{C}-003\end{array}$

4. Title and Subtitle

2. Government Accession No.

3. Recipient's Catalog No.

NASA Low-Speed Centrifugal Compressor for 3-D Viscous

Code Assessment and Fundamental Flow Physics Research

5. Report Date

6. Performing Organization Code

7. Author(s)

M.D. Hathaway, J.R. Wood, and C.A. Wasserbauer

8. Performing Organization Report No.

E-5938

10. Work Unit No.

9. Performing Organization Name and Address

505-62-21

NASA Lewis Research Center

1L161102AH45

Cleveland, Ohio 44135-3191

11. Contract or Grant No.

and

Propulsion Directorate

U.S. Army Aviation Systems Command

Cleveland, Ohio 44135-3191

12. Sponsoring Agency Name and Address

National Aeronautics and Space Administration

Washington, D.C. 20546-0001

and

U.S. Army Aviation Systems Command

St. Louis, Mo. 63120-1798

15. Supplementary Notes

Prepared for the 36th International Gas Turbine and Aeroengine Congress and Exposition sponsored by the American Society of Mechanical Engineers, Orlando, Florida, June 3-6, 1991. M.D. Hathaway, Propulsion Directorate, U.S. Army Aviation Systems Command. J.R. Wood, NASA Lewis Research Center. C.A. Wasserbauer, Sverdrup Technology, Inc., Lewis Research Center Group, 2001 Aerospace Parkway, Brook Park, Ohio 44142. Responsible person, M.D. Hathaway, (216) 433-6250.

16. Abstract

A low speed centrifugal compressor facility recently built by the NASA Lewis Research Center is described. The purpose of this facility is to obtain detailed flow field measurements for computational fluid dynamic code assessment and flow physics modelling in support of Army and NASA efforts to advance small gas turbine engine technology. The facility is heavily instrumented with pressure and temperature probes, both in the stationary and rotating frames of reference, and has provisions for flow visualization and laser velocimetry. The facility will accommodate rotational speeds to $2400 \mathrm{rpm}$ and is rated at pressures to 1.25 atm. The initial compressor stage being tested is geometrically and dynamically representative of modern high-performance centrifugal compressor stages with the exception of Mach number levels. Preliminary experimental investigations of inlet and exit flow uniformity and measurement repeatability are presented. These results demonstrate the high quality of the data which may be expected from this facility. The significance of synergism between computational fluid dynamic analyses and experimentation throughout the development of the low speed centrifugal compressor facility is demonstrated.

17. Key Words (Suggested by Author(s))

Centrifugal compressor

Low speed

Experiment

Computation
18. Distribution Statement

Unclassified - Unlimited

Subject Category 02

19. Security Classif. (of this report)

Unclassified

20. Security Classif. (of this page)

Unclassified

21. No. of pages

22. Price*

14

$\mathrm{A} 03$ 